\title{
Association of cognitive dietary restraint and disinhibition with prediabetes - cross-sectional and longitudinal data of a feasibility study in German employees
}

\author{
Birgit-Christiane Zyriax ${ }^{1, *}$, Christina Wolf ${ }^{1}$, Annika Schlüter ${ }^{1}$, Asad Hameed Khattak ${ }^{2}$, \\ Joachim Westenhoefer ${ }^{2}$ and Eberhard Windler ${ }^{1}$ \\ 'University Medical Center Hamburg, Martinistrasse 52 N36, D-20246 Hamburg, Germany: ${ }^{2}$ Department of \\ Health Science, Faculty of Life Sciences, Hamburg University of Applied Sciences, Hamburg, Germany
}

Submitted 24 February 2011: Accepted 22 August 2011: First published online 29 September 2011

\begin{abstract}
Objective: To investigate the impact of eating behaviour traits on central obesity, prediabetes and associated major dietary food patterns.

Design: Assessment of eating behaviour was based on the revised German version of the Three-Eating Factor Questionnaire using cross-sectional and longitudinal data of a feasibility study in employees. Data on lifestyle and nutrition were obtained by validated self-administered questionnaires. Baseline characteristics were analysed by the univariate $\chi^{2}$ test or the Mann-Whitney test. To quantify correlations linear regression analysis was used.

Setting: The Delay of Impaired Glucose Tolerance by a Healthy Lifestyle Trial (DELIGHT), which investigated measures to prevent type 2 diabetes mellitus in 2004-2008.

Subjects: Employees (21-64 years, 127 men, 157 women) with elevated waist circumference (men $\geq 94 \mathrm{~cm}$, women $\geq 80 \mathrm{~cm}$ ) of five medium-sized companies in northern Germany.

Results: At baseline (T0), BMI but particularly waist circumference showed a strong inverse correlation with flexible control $(P<0 \cdot 0001)$ and a positive correlation with disinhibition $(P<0 \cdot 0001)$ and rigid control $(P=0 \cdot 063)$. Flexible control was also significantly inversely related to fasting plasma glucose $(P=0 \cdot 040)$, energy intake $(P<0 \cdot 0001)$, intake of meat and meat products $(P=0 \cdot 0001)$, and positively associated with intake of fruit and vegetables $(P<0 \cdot 0001)$ at baseline (T0). Changes in flexible control within the first year of intervention (T1 $v$. T0) predicted changes in central obesity $(P<0 \cdot 0001)$ and fasting plasma glucose $(P=0 \cdot 025)$.

Conclusions: DELIGHT shows that flexible control characterizes individuals with a higher dietary quality, a lower waist circumference and a lower glucose level. Enhancing flexible control more than rigid control, and decreasing disinhibition, seems beneficial in terms of central adiposity and glucose levels.
\end{abstract}

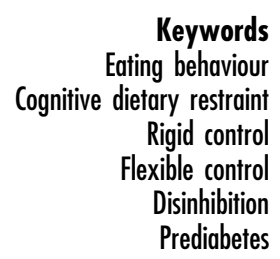

The prevalence of type 2 diabetes mellitus is increasing dramatically and represents a growing health problem in most parts of the world ${ }^{(1-4)}$. The underlying issue appears to be an inadequate eating behaviour in an environment of declining physical activity. Even in individuals with prediabetes, defined as blood glucose levels above the upper limit of normal but below the definition of diabetes, the risk for cardiovascular events and total mortality is nearly doubled ${ }^{(5-10)}$. Some 5 to $10 \%$ of these prediabetic patients develop diabetes each year ${ }^{(11,12)}$. However, in routine medical practice, prediabetes is not yet recognized nor treated.

Besides a genetic predisposition, both an unhealthy dietary pattern and a sedentary lifestyle promote weight gain and increase visceral fat mass, leading to prediabetes and associated components of the metabolic syndrome. In various populations previous studies suggest that eating behaviour traits correlate with body weight ${ }^{(13-15)}$. Most studies suggest that high levels of restraint eating but also of disinhibition are positively associated with a higher BMI and weight gain over time. Divergent results may be attributable to the subsequent finding that dietary restraint is not a homogeneous construct. It encompasses two distinct behavioural subscales of eating behaviour: rigid control, characterized by an 'all or nothing' approach, and flexible control, which comprises a 'more or less' approach to weight and eating ${ }^{(16,17)}$. In studies validating these psychological constructs, rigid control was associated 
with a higher BMI and disordered eating patterns, whereas flexible control was associated with a lower BMI and a more pronounced weight loss ${ }^{(18-22)}$. However, information on the association between cognitive control and central obesity, prediabetes and dietary food patterns is currently limited.

This prompted us to analyse data of young employees in the Delay of Impaired Glucose Tolerance by a Healthy Lifestyle Trial (DELIGHT) to investigate the predictive value of eating behaviour traits with regard to anthropometric parameters, blood glucose levels and major dietary patterns by using the revised German version of the Three-Eating Factor Questionnaire ${ }^{(16,23)}$.

\section{Methods}

\section{Design and recruitment}

DELIGHT is a feasibility study on sustainable prevention of diabetes in young men and women. Between 2004 and 2005 employees of five medium-sized companies (health insurance, wharf, camper manufacturer, food industry, medical equipment supplier) in the northern part of Germany were informed about the impact of prediabetes and the chance of preventing diabetes and associated risk factors through lifestyle modification via flyers, intranet and on the occasion of work meetings. Employees aged 18-65 years were advised how to measure their waist circumference and were invited for a medical check-up if the self-measured waist circumference was close to or above the cut-off point of $94 \mathrm{~cm}$ for men or $80 \mathrm{~cm}$ for women.

Employees with as yet undiagnosed type 2 diabetes mellitus, or classified as prediabetic individuals by fasting plasma glucose $\geq 100 \mathrm{mg} / \mathrm{dl}$ or plasma glucose $\geq 140 \mathrm{mg} / \mathrm{dl}$ two hours after $75 \mathrm{~g}$ of glucose, were offered optional weekly group sessions based on the current evidence for diabetes prevention, including dietary advice and walking during the first year, particularly during the first three months ${ }^{(10,24)}$

Goals of the initial treatment comprised a weight loss of at least $5 \%$ by reducing energy intake, a reduction in the intakes of total fat $(<30 \%$ of energy) and saturated fat $(<10 \%)$ by a lower consumption of meat and meat products, an increase in fibre intake by a higher consumption of fruit and vegetables, and regular physical activity of at least 30 min on most days according to Lindström et $\mathrm{al}^{(24)}$. Adherence to four out of these five goals has been shown to lower the risk to zero after 1 year ${ }^{(25)}$, even long term ${ }^{(26)}$.

Standard behaviour therapy, adapted from Westenhoefer et $a l .{ }^{(16,18)}$, was part of the dietary counselling. Participants were motivated to develop flexible control, i.e. moderate eating control depending on the situation according to a 'more or less' approach. On the other hand, participants were encouraged to reduce rigid control by dieting according to strict rules, which is often followed by periods lacking any control reflecting an 'all or nothing' approach. Instead of totally avoiding fatty foods, sweets, snacks or sweetened beverages, participants were advised to consume unhealthy foods less often or in limited amounts (flexible control). The participants also were taught how to cope with situations that might induce disinhibition and how to prevent relapses. They learned how to identify and in a second step to overcome intrinsic or extrinsic stimuli for overeating such as boredom, stress or the presence of tasty food by trying to find alternatives. Relapse prevention included realistic goal setting, identification of potential causes with regard to weight regain and the ability to counter as early and efficiently as possible. After the initial phase participants were offered a follow-up for 2 years including booster sessions every three months.

Exclusion criteria were known pregnancy, known type 1 or 2 diabetes mellitus, and acute malignant or severe chronic disease. The final study population comprised 300 participants. However, the present analysis focuses on the data at screening of 127 men and 157 women (T0) and at a follow-up visit one year after the screening (T1) in twenty-three prediabetic men and twenty-one women who completed the Three-Factor Eating Questionnaire. The study protocol was approved by the ethical committee of Hamburg and conducted according to the principles of the Declaration of Helsinki. Written informed consent was obtained from all participants.

\section{Data collection}

Data on lifestyle, nutrition, sociodemographic characteristics and family history of diabetes were obtained using validated questionnaires developed for the EPIC (European Prospective Investigation into Cancer and Nutrition) study, a prospective multicentre cohort study in Europe, investigating the association between lifestyle factors and chronic diseases ${ }^{(27-29)}$. A self-administered food questionnaire recorded the frequency and portion size of 146 food items eaten during the preceding year.

Information about eating behaviour was obtained by using the revised German version of the Three-Eating Factor Questionnaire, based on fifty-six questions. The present analysis focuses on the evaluation of rigid and flexible control as relevant subscales for cognitive dietary restraint, and of disinhibition ${ }^{(16,23)}$. Dietary restraint describes the behavioural tendency to restrict food intake in order to lose weight or to maintain weight loss. Rigid control and flexible control are subscales of dietary restraint which are correlated although they describe contrasting features of dietary restraint (see introduction). Rigid control and flexible control, although contrasting, are not exclusive. Disinhibition describes the tendency to overeat in response to environmental or emotional stimuli. The questionnaire comprised twenty-one questions with regard to cognitive dietary restraint, sixteen as to rigid control, thirteen as to flexible control and sixteen as to disinhibition ${ }^{(16)}$. For each question none or one point could be obtained. A low score encompasses that the trait is less pronounced compared with a high score. 
Height and weight were measured to the nearest $0.5 \mathrm{~cm}$ or $0 \cdot 1 \mathrm{~kg}$, respectively, and BMI was calculated as weight $(\mathrm{kg}) /$ height $(\mathrm{m})]^{2}$. Waist circumference was measured midway between the lower rib margin and the iliac crest. Central obesity was defined by a waist circumference $\geq 80 \mathrm{~cm}$ in women and $\geq 94 \mathrm{~cm}$ in men. A fasting morning blood sample was taken and an oral glucose tolerance test (OGTT) was performed using a glucose load of $75 \mathrm{~g}$. All blood samples were transported in NaF-containing Monovette tubes (Eppendorf, Hamburg, Germany) and blood values were determined by standard techniques in the central laboratory of the University Medical Center Hamburg. Prediabetes was defined as a fasting plasma glucose level between 100 and $125 \mathrm{mg} / \mathrm{dl}$ (impaired fasting glucose, IFG) and/or a plasma glucose level between 140 and $199 \mathrm{mg} / \mathrm{dl}$ two hours after ingesting $75 \mathrm{~g}$ glucose in the OGTT (impaired glucose tolerance, IGT) ${ }^{(10)}$. Diabetes was defined as a fasting plasma glucose level $\geq 126 \mathrm{mg} / \mathrm{dl}$ and/or plasma glucose level $\geq 200 \mathrm{mg} / \mathrm{dl}$ two hours after ingesting $75 \mathrm{~g}$ glucose in the OGTT. Blood pressure was taken in a sitting position three times approximately 2 min apart, of which the second and third values were averaged ${ }^{(30)}$. For the definition of the metabolic syndrome, the criteria of the International Diabetes Federation were adopted (www.idf.org).

\section{Statistical analyses}

Baseline characteristics of the participants were analysed with the univariate $\chi^{2}$ test or the Mann-Whitney test, as appropriate. To quantify correlations between eating behaviour traits, clinical data and dietary patterns, linear regression analysis was used. $P$ values below $0 \cdot 05$ were considered statistically significant. Statistical calculations were performed running the XLSTAT software version 2009 (Addinsoft, Andernach, Germany).

\section{Results}

\section{Baseline characteristics}

Characteristics of the study population at baseline (T0) are given in Table 1. Due to the inclusion criterion of an elevated waist circumference, mean fasting glucose levels were elevated slightly in both genders. Compared with men, women were characterized by significantly lower systolic blood pressure, LDL-cholesterol and TAG levels and higher HDL-cholesterol levels. Compared with women, men reported a higher intake of energy particularly as meat and meat products and a lower consumption of fruit and vegetables. Women had significantly higher scores for both rigid control and flexible control than men, whereas scores for disinhibition did not differ between genders (Table 1).

\section{Eating behaviour and clinical parameters}

BMI and waist circumference clearly correlated with the extent of flexible control, rigid control and disinhibition at T0. In the total population and separately in both genders, a significant inverse correlation between flexible control and BMI was observed (regression coefficient, $r=-0 \cdot 27$, $P=0.005$ in total population; $r=-0 \cdot 28, P=0.024$ in men; $r=-0 \cdot 30, P=0 \cdot 002$ in women). In contrast, rigid control (total: $r=0 \cdot 34, \quad P=0 \cdot 0001$; men: $r=0 \cdot 34, \quad P=0 \cdot 001$; women: $r=0 \cdot 35, P=0 \cdot 018)$ and even more so disinhibition (total: $r=0 \cdot 58, P<0 \cdot 0001$; men: $r=0 \cdot 46, P<0 \cdot 0001$; women: $r=0 \cdot 66, P<0 \cdot 0001)$ were positively correlated with BMI in the total population and in the subgroups.

Waist circumference was even more strongly correlated than BMI with all eating behaviour traits at T0. In the total study population and separately in both genders, a strong inverse association between flexible control and waist circumference was revealed (total: $r=-1 \cdot 32, \quad P<0 \cdot 0001$;

Table 1 Baseline (TO) clinical characteristics, dietary patterns and eating behaviour among German employees aged 21-64 years, Delay of Impaired Glucose Tolerance by a Healthy Lifestyle Trial (DELIGHT), 2004-2008

\begin{tabular}{|c|c|c|c|c|c|}
\hline & \multicolumn{2}{|c|}{ Men $(n$ 127) } & \multicolumn{2}{|c|}{ Women (n 157) } & \multirow[b]{2}{*}{$P$ value } \\
\hline & Mean & SD & Mean & SD & \\
\hline \multicolumn{6}{|l|}{ Clinical characteristics } \\
\hline Age (years) & $44 \cdot 1$ & $9 \cdot 0$ & $43 \cdot 7$ & $8 \cdot 5$ & NS \\
\hline BMI $\left(\mathrm{kg} / \mathrm{m}^{2}\right)$ & $28 \cdot 8$ & $3 \cdot 4$ & $28 \cdot 8$ & $5 \cdot 7$ & NS \\
\hline Waist circumference $(\mathrm{cm})$ & $100 \cdot 9$ & $9 \cdot 6$ & $89 \cdot 8$ & $11 \cdot 4$ & $<0.0001$ \\
\hline HDL-cholesterol (mg/dl) & 56 & 13 & 66 & 17 & $<0.0001$ \\
\hline LDL-cholesterol (mg/dl) & 136 & 35 & 117 & 29 & $<0.0001$ \\
\hline Systolic blood pressure $(\mathrm{mmHg})$ & 129 & 14 & 125 & 16 & 0.003 \\
\hline Diastolic blood pressure (mmHg) & 83 & 9 & 81 & 10 & NS \\
\hline Prevalence of metabolic syndrome (\%) & \multicolumn{2}{|c|}{40} & \multicolumn{2}{|c|}{34} & NS \\
\hline Intake of fruit and vegetables $(\mathrm{g} / \mathrm{dl})$ & 400 & 181 & 439 & 215 & NS \\
\hline Rigid control (score, points) & $4 \cdot 2$ & $3 \cdot 0$ & $5 \cdot 2$ & $3 \cdot 0$ & 0.006 \\
\hline Flexible control (score, points) & $3 \cdot \overline{3}$ & $2 \cdot 5$ & $4 \cdot \overline{9}$ & $3 \cdot 0$ & $<0.0001$ \\
\hline Disinhibition (score, points) & $6 \cdot 1$ & $2 \cdot 8$ & $6 \cdot 2$ & $2 \cdot 9$ & NS \\
\hline
\end{tabular}


(a)

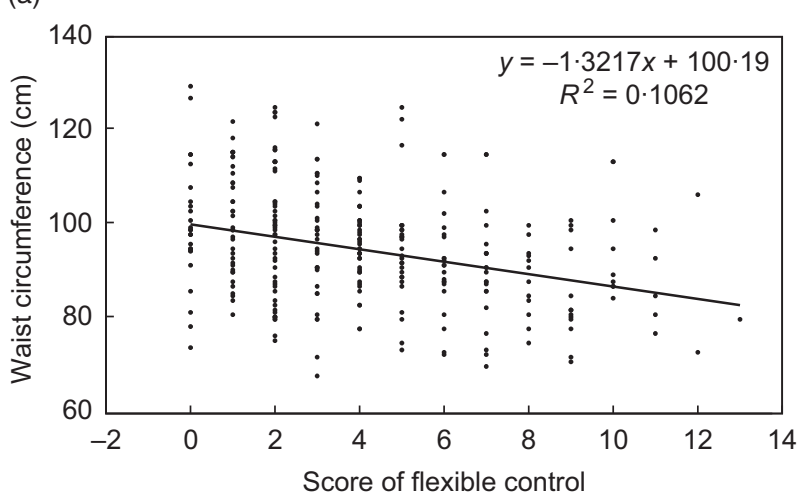

(b)

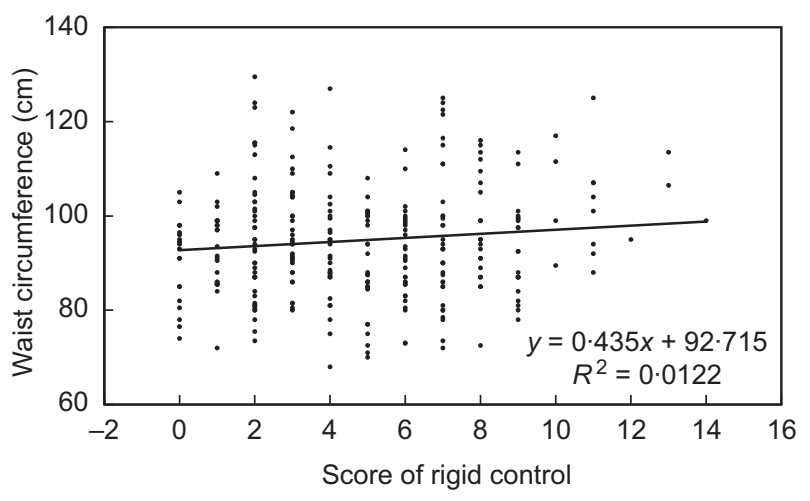

(c)

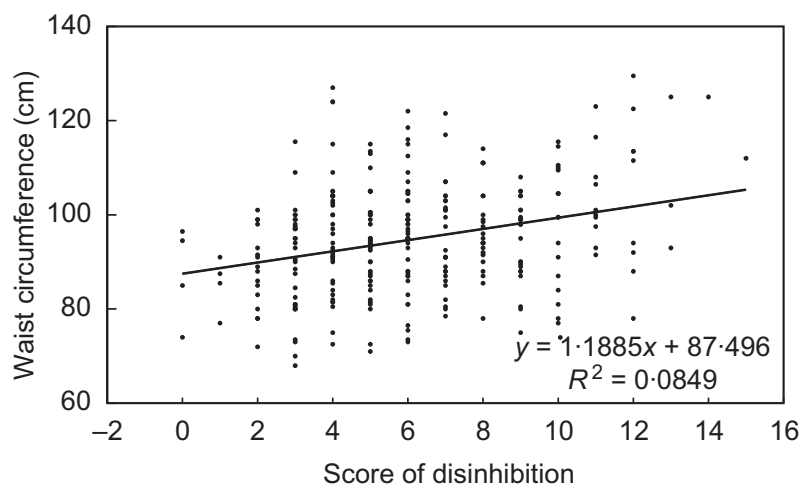

Fig. 1 Association of flexible control (a), rigid control (b) and disinhibition (c) with waist circumference in the total study population at baseline (T0): German employees aged 21-64 years, Delay of Impaired Glucose Tolerance by a Healthy Lifestyle Trial (DELIGHT), 2004-2008

men: $r=-0 \cdot 89, P=0 \cdot 009$; women: $r=-0 \cdot 91, P=0 \cdot 002$; Fig. 1(a)). Rigid control and waist circumference were correlated positively in both genders, while the trend was weaker in the total population (total: $r=0.44, P=0.063$; men: $r=0 \cdot 72, P=0 \cdot 011$; women: $r=0 \cdot 72, P=0 \cdot 017$; Fig. $1(b))$. Moreover, a strong positive and significant correlation was revealed between disinhibition and waist circumference in the total population and both subgroups (total: $r=1 \cdot 19, P<0 \cdot 0001$; men: $r=0 \cdot 90, P=0 \cdot 002$; women: $r=1 \cdot 44, P<0 \cdot 0001$; Fig. 1(c)).

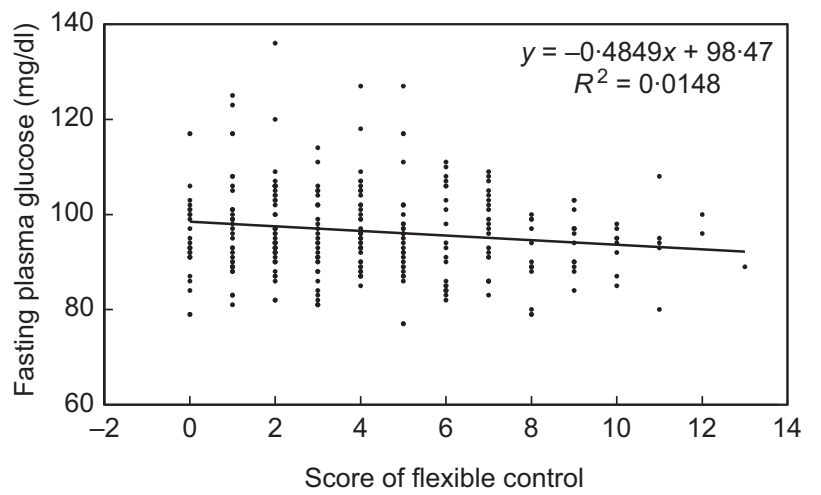

Fig. 2 Association of flexible control with fasting plasma glucose levels in the total study population at baseline (T0): German employees aged 21-64 years, Delay of Impaired Glucose Tolerance by a Healthy Lifestyle Trial (DELIGHT), 2004-2008

With regard to laboratory values only flexible control was significantly and strongly inversely correlated with fasting plasma glucose $(r=-0 \cdot 49, P=0 \cdot 040$; Fig. 2) and TAG levels $(r=-4.73, P=0.004)$ in the total study population at T0. In women, a significant positive association of rigid control and disinhibition with TAG levels was observed too (rigid control: $r=4 \cdot 52, \quad P=0 \cdot 003$; disinhibition: $r=3 \cdot 29, P=0 \cdot 033$ ).

More men than women were affected by parameters of the metabolic syndrome at T0 (Table 1). The extent of flexible control differed between those participants with the metabolic syndrome compared with participants without this characteristic (mean score: $3 \cdot 0 \quad v$. $4 \cdot 0$, $P=0 \cdot 016)$. Thus, higher flexible control was associated with lower prevalence of the metabolic syndrome in the total study population. No association was found between rigid control or disinhibition and the metabolic syndrome.

\section{Eating behaviour and dietary patterns}

At T0 flexible control was inversely associated with energy intake $(r=-237 \cdot 5, P<0 \cdot 0001)$ and the intake of meat and meat products $(r=-5 \cdot 45, P=0 \cdot 0001)$ in the total population (Figs 3(a) and 3(b)). The same trends were observed if men and women were analysed separately, but failed to show significance. In contrast, a positive relationship was found between the extent of flexible control and the intake of fruit and vegetables in the total population $(r=17.9, \quad P<0.0001$; Fig. 3(c)), also in men $(r=14.9$, $P=0.023)$ and women $(r=18 \cdot 6, P=0.002)$. An inverse correlation was revealed between rigid control and energy intake $(r=-220 \cdot 0, P<0 \cdot 0001)$ and a positive association between rigid control and intake of fruit and vegetables ( $r=10 \cdot 7, P=0 \cdot 011$ ) in the total population. A positive trend between disinhibition and the intake of meat and meat products was also observed in both genders, but was significant only in women $(r=3 \cdot 06, P=0 \cdot 042)$. 
(a)

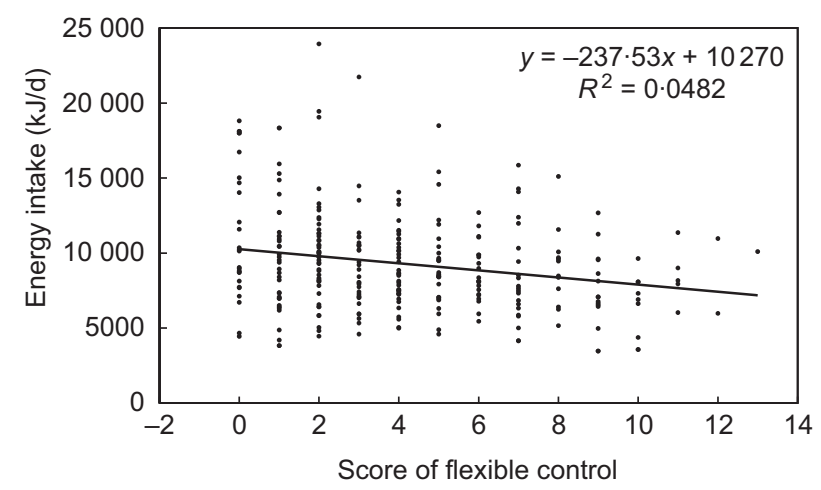

(b)

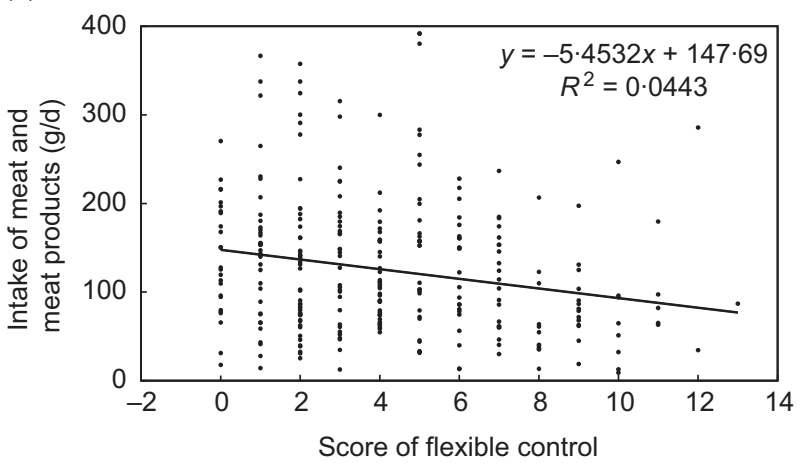

(c)

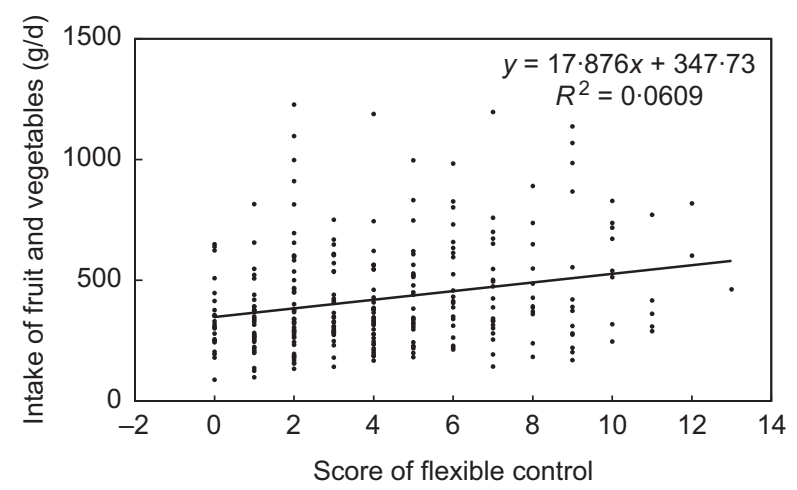

Fig. 3 Association of flexible control with energy intake (a), intake of meat and meat products (b) and intake of fruit and vegetables (c) in the total study population at baseline (TO): German employees aged 21-64 years, Delay of Impaired Glucose Tolerance by a Healthy Lifestyle Trial (DELIGHT), 2004-2008

\section{Impact of eating behaviour within 1 year}

Of the 240 out of 300 employees with an elevated waist circumference screened at T0, 34\% ( $n$ 80) were characterized by prediabetes and a further $3 \%(n)$ had as yet undiagnosed type 2 diabetes mellitus. Forty-four employees completed the Three-Factor Eating Questionnaire at T0 and T1. Differences in flexible control and rigid control between T1 and T0 were clearly inversely correlated with differences in BMI and waist circumference
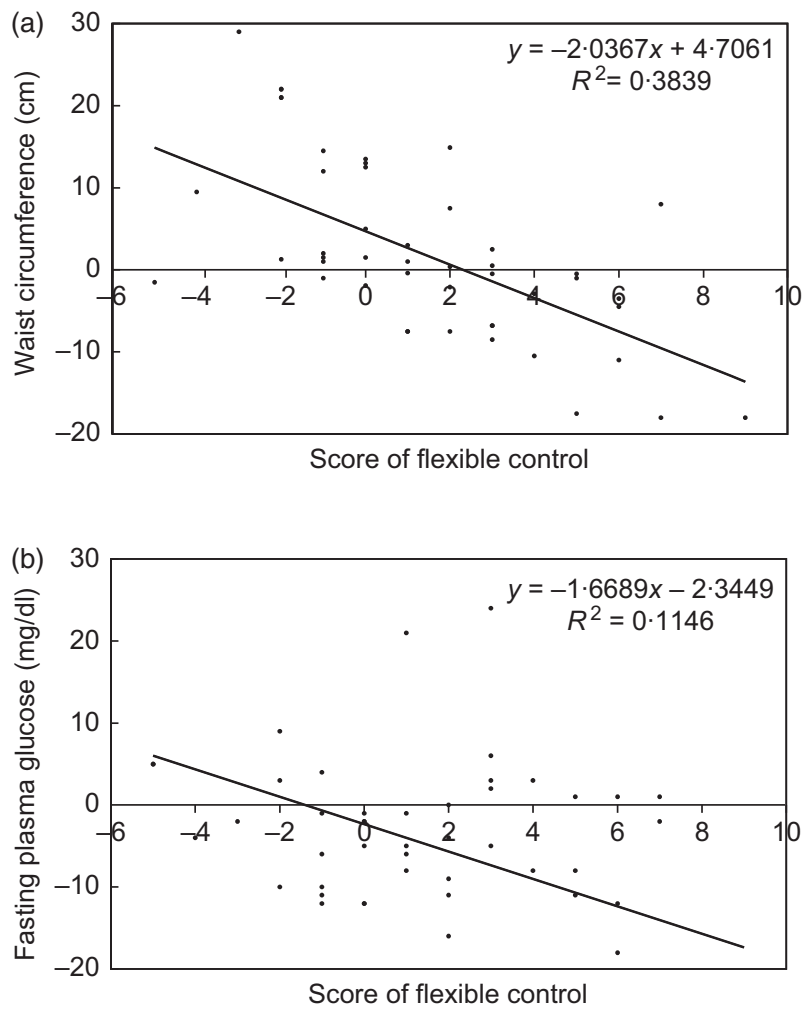

Fig. 4 Association of changes in flexible control (T1 v. T0) with changes in waist circumference (a) and changes in fasting plasma glucose levels (outlying data point 9/-89 not shown) (b) in the total study population: German employees aged 21-64 years, Delay of Impaired Glucose Tolerance by a Healthy Lifestyle Trial (DELIGHT), 2004-2008

(Fig. 4(a)). For BMI, the correlation was much stronger for flexible control $(r=-0 \cdot 31, P<0 \cdot 0001)$ than for rigid control $(r=-0 \cdot 17, P=0.039)$. However, in terms of waist circumference, correlations for both flexible control $(r=-2 \cdot 04, \quad P<0 \cdot 0001)$ and rigid control $(r=-1 \cdot 36$; $P=0.007)$ were even stronger. In line with these findings the difference in flexible control between $\mathrm{T} 1$ and $\mathrm{T} 0$ was also inversely related to the change in fasting plasma glucose from T0 to T1 $(r=-1 \cdot 67, P=0 \cdot 025$; Fig. 4(b)).

\section{Discussion}

The present analysis of DELIGHT data showed a strong correlation between eating behaviour traits and anthropometric parameters. Furthermore, the extent of flexible control was inversely related to plasma glucose levels and major dietary patterns known to play a decisive role in the prevention of diabetes. Also, follow-up data clearly indicated that differences in eating traits between T1 and T0 correlated significantly with changes in anthropometric parameters and fasting plasma glucose levels.

Baseline characteristics at T0 demonstrated that mean fasting plasma glucose levels in both genders were close 
to $100 \mathrm{mg} / \mathrm{dl}$, by definition the cut-off point for prediabetes. However, compared with women, men were characterized by more unhealthy food choices and an unfavourable cardiovascular risk profile including central obesity, systolic blood pressure and levels of LDLcholesterol, HDL-cholesterol and TAG, in line with other investigations. Consistently, scores of flexible control, but also rigid control, were significantly higher in women compared with men. An impact of gender on the level of cognitive dietary restraint is supported by data from other investigations ${ }^{(20,31)}$

At T0 a positive and significant correlation between rigid control and disinhibition with BMI was documented, whereas the relationship of flexible control and BMI was inverse. These findings are in accordance with most, but not all investigators ${ }^{(17,19,20,32)}$. In the Quebéc Family Study $^{(20)}$ rigid and flexible control were oppositely associated with obesity status as in DELIGHT. Bellisle et al. demonstrated that disinhibition was the factor most strongly associated with BMI, particularly in individuals with a low level of dietary restraint ${ }^{(33)}$. Gallant et al. showed in adolescents that rigid control and disinhibition were independently related to BMI scores ${ }^{(22)}$. Hays et al. found that high scores of flexible control attenuated the relationship between disinhibition and weight gain, and that rigid control was not significantly associated ${ }^{(34)}$. However conflicting results with regard to body weight variations may be caused by ethnic differences, the degree of obesity, self-reported weight or, probably most importantly, focusing on cognitive dietary restraint without differentiating between subscales ${ }^{(20,34-37)}$.

Similar to BMI, DELIGHT showed a clear positive correlation between rigid control and disinhibition with waist circumference, whereas flexible control was inversely related at T0. Only a few studies have evaluated the relationship between eating behaviour traits and central obesity. In the Québec Family Study positive correlations were observed between rigid control and most of the anthropometric variables. However only in women flexible control was inversely associated with waist circumference, and no relationship between disinhibition and central obesity was found ${ }^{(20)}$. In a sample of Czech adults dietary restraint was negatively and disinhibition positively related to waist circumference ${ }^{(32)}$.

Regarding anthropometric-dependent laboratory values, in DELIGHT flexible control was strongly inversely correlated with fasting plasma glucose and TAG levels in the total study population at T0. This certainly fits the data on waist circumference. Rigid control and disinhibition had no measurable influence, though. A clear relationship between dietary restraint, hyperlipidaemia and diabetes was documented only in a sample of Czech adults ${ }^{(32)}$. In restrained eaters Keim and Horn reported that fasting insulin concentrations were lower ${ }^{(38)}$.

In the present analysis, at T0 eating behaviour traits were not only strongly related to anthropometric and laboratory values, but also to major dietary patterns known to influence the risk of type 2 diabetes mellitus, such as intake of meat and meat products and intake of fruit and vegetables as a protective factor. In terms of energy this is in line with data from Westenhoefer et al., which indicate that flexible control was associated with a lower self-reported intake of energy in a West German population $^{(17)}$. In a sample of university students in Portugal high-restraint eaters reported a lower intake of energy and a higher intake of vegetables ${ }^{(39)}$.

Also, postmenopausal women with high restraint and low disinhibition had a lower consumption of red and processed meat and a higher intake of whole grains ${ }^{(40)}$. In patients with newly diagnosed diabetes mellitus van Strien et al. demonstrated that increases in restrained eating were associated with decreases in fat and saturated fat intakes after 4 years $^{(41)}$. In a randomized weightloss programme Keränen et al. reported that cognitive restraint was associated with lower energy and fat intakes, whereas carbohydrates and fibre intakes were higher ${ }^{(42)}$. In a review from Bryant et al. disinhibition was reported to be associated with a less healthy food choice ${ }^{(15)}$. In contrast, the analysis of the Québec Family Study showed that dietary macronutrient content was not consistently related to eating behaviour traits in adolescents ${ }^{(22)}$. However, previous research did not include prediabetic patients and mostly focused on dietary restraint instead of evaluating subscales.

Certainly an interesting finding of DELIGHT is that changes of eating behaviour traits, particularly flexible control, within the first year of intervention (T1 $v$. T0) correlated with changes in anthropometric parameters and glucose levels. The beneficial trends may indicate the impact of the instructions on the change of dietary habits during the first year of intervention. Unfortunately the small sample size in the follow-up does not allow us to evaluate the effect of changes in flexible control and dietary intake. However, data of the screening indicate that higher flexible control is positively correlated with the intake of fruits and vegetables and inversely with the amount of meat and processed meat. These findings indicate that motivating patients to adopt flexible control will not only enhance weight control, but may also be an effective measure to prevent type 2 diabetes.

An increase in total restraint, flexible control or rigid control has been shown also by others to predict weight changes over time ${ }^{(43-45)}$. However, with regard to BMI, the role of flexible control seems to be prevailing as in DELIGHT ${ }^{(17,18,46)}$. Interestingly, in DELIGHT eating behaviour traits at T0, particularly flexible control, were much more closely related to waist circumference, a strong indicator of diabetes risk, than to BMI. This fits with the correlation of flexible control and fasting plasma glucose at $\mathrm{T} 0$ and is in line with the observation of an inverse correlation of changes in flexible control and fasting plasma glucose levels between $\mathrm{T} 0$ and $\mathrm{T} 1$. 


\section{Study limitations}

DELIGHT has limitations that need to be addressed. First, our findings are confined to those employees who voluntarily chose to take part in the programme. Second, the intervention was offered to all participants, since within the companies randomization into a control group was considered appropriate. Third, the analysis of follow-up data within the first year is based on a small sample and therefore associations between differences in disinhibition and changes in anthropometry or laboratory data may have been missed.

\section{Conclusions}

DELIGHT demonstrates that particularly central obesity, blood glucose levels and major dietary patterns correlate strongly with the extent of flexible control. Also, changes in flexible control within the first year of intervention predicted changes in BMI, waist circumference and fasting plasma glucose. Thus, the results of DELIGHT suggest that the evaluation of dietary behaviour traits is useful to identify individuals at risk for diabetes and therefore may be introduced into the routine assessment of dietary habits. Furthermore, emphasis on strategies to adopt flexible control may improve long-term success in a diabetes prevention programme. Certainly, only randomized controlled trials can confirm these findings and establish cause and effect.

\section{Acknowledgements}

Financial support of DELIGHT was primarily given by the health assurance 'AOK NordWest - Die Gesundheitskasse'. All authors have appropriately disclosed conflicts of interest according to journal policy and no competing financial interests exist. B.-C.Z. designed the study and wrote the paper; C.W. collected and analysed the data; A.S. performed analysis of the data; A.H.K. performed analysis of the data; J.W. participated in the design and provided methodical help; E.W. designed and performed the study. All authors read and approved the final manuscript. The authors are indebted to all participants of the study for their collaboration.

\section{References}

1. King H, Aubert RE \& Herman WH (1998) Global burden of diabetes, 1995-2025: prevalence, numerical estimates, and projections. Diabetes Care 21, 1414-1431.

2. Turner RC, Millns H, Neil HA et al. (1998) Risk factors for coronary artery disease in non-insulin dependent diabetes mellitus: United Kingdom Prospective Diabetes Study (UKPDS 23). BMJ 316, 823-828.

3. The DECODE Study Group (2001) Glucose tolerance and cardiovascular mortality: comparison of fasting and 2-hour diagnostic criteria. Arch Intern Med 161, 397-405.

4. Eastman RC, Cowie CC \& Harris MI (1997) Undiagnosed diabetes or impaired glucose tolerance and cardiovascular risk. Diabetes Care 22, 233-240.
5. Coutinho M, Gerstein HC \& Wang YS (1999) The relationship between glucose and incident cardiovascular events: a metaregression analysis of published data from 20 studies of 95,783 individuals followed for 12.4 years. Diabetes Care 22, 233-240.

6. Port SC, Goodarzi MO, Boyle NG et al. (2005) Blood glucose: a strong risk factor for mortality in nondiabetic patients with cardiovascular disease. Am Heart J 150, 209-214.

7. Qiao Q, Jousilahti P, Eriksson J et al. (2003) Predictive properties of impaired glucose tolerance for cardiovascular risk are not explained by the development of overt diabetes during follow-up. Diabetes Care 26, 2910-2914.

8. Zyriax BC, Boeing $\mathrm{H}$ \& Windler E (2005) Nutrition is a powerful independent risk factor for coronary heart disease in women - The CORA study: a population-based case-control study. Eur J Clin Nutr 59, 1201-1207.

9. Barr EL, Zimmet PZ, Welborn TA et al. (2007) Risk of cardiovascular and all-cause mortality in individuals with diabetes mellitus, impaired fasting glucose, and impaired glucose tolerance: the Australian Diabetes, Obesity, and Lifestyle Study (AusDiab). Circulation 116, 151-157.

10. American Diabetes Association (2010) Diagnosis and classification of diabetes mellitus. Diabetes Care 33, Suppl. 1, S62-S69.

11. de Vegt F, Dekker JM, Jager A et al. (2001) Relation of impaired fasting and postload glucose with incident type 2 diabetes in a Dutch population: the Hoorn Study. JAMA 285, 2109-2113.

12. Diabetes Prevention Program (DPP) Research Group (2002) The Diabetes Prevention Program (DPP) description of lifestyle intervention. Diabetes Care 25, 2165-2171.

13. Mumford SL, Siega-Riz AM, Herring A et al. (2008) Dietary restraint and gestational weight gain. J Am Diet Assoc 108, 1646-1653.

14. Schur EA, Heckbert SR \& Goldberg JH (2010) The association of restrained eating with weight change over time in a community-based sample of twins. Obesity (Silver Spring) 18, 1146-1152.

15. Bryant EJ, King NA \& Blundell JE (2008) Disinhibition: its effects on appetite and weight regulation. Obes Rev 9, 409-419.

16. Westenhoefer J (1991) Dietary restraint and disinhibition: is restraint a homogeneous construct? Appetite 16, 45-55.

17. Westenhoefer J, Stunkard AJ \& Pudel V (1999) Validation of the flexible and rigid control dimensions of dietary restraint. Int J Eat Disord 26, 53-64.

18. Westenhoefer J (2001) The therapeutic challenge: behavioral changes for long-term weight maintenance. Int J Obes Relat Metab Disord 25, Suppl. 1, S85-S88.

19. Shearin EN, Russ MJ \& Hull JW (1994) Construct validity of the Three-Factor Eating Questionnaire: flexible and rigid control subscales. Int J Eat Disord 16, 187-198.

20. Provencher V, Drapeau V \& Tremblay A (2003) Eating behaviors and indexes of body composition in men and women from the Québec family study. Obes Res 11, 783-792.

21. Riesco E, Rossel N \& Rusques C (2010) Impact of weight reduction on eating behaviors and quality of life: Influence of the obesity degree. Obes Facts 2, 87-95.

22. Gallant AR, Tremblay A \& Pérusse L (2010) The ThreeFactor Eating Questionnaire and BMI in adolescents: results from the Québec Family Study. Br J Nutr 104, 1074-1079.

23. Pudel V \& Westenhöfer J (1989) Fragebogen zum Essverhalten: Handanweisung. Göttingen: Hogrefe.

24. Lindström J, Louheranta A, Mannelin $\mathrm{M}$ et al. for the Finnish Diabetes Prevention Study Group (2003) The Finnish Diabetes Prevention Study (DPS): lifestyle intervention and 3 -year results on diet and physical activity. Diabetes Care 26, 3230-3236.

25. Tuomilehto J, Lindström J, Eriksson JG et al. for the Finnish Diabetes Prevention Study Group (2001) Prevention of type 2 diabetes mellitus by changes in lifestyle among 
subjects with impaired glucose tolerance. $N$ Engl J Med 344, 1343-1350

26. Lindström J, Ilanne-Parikka $\mathrm{P}$, Peltonen $\mathrm{M}$ et al. for the Finnish Diabetes Prevention Study Group (2006) Sustained reduction in the incidence of type 2 diabetes by lifestyle intervention: follow-up of the Finnish Diabetes Prevention Study. Lancet 1368, 1673-1679.

27. Bohlscheid TS, Hoting I, Boeing H et al. (1997) Reproducibility and relative validity of food group intake in a food frequency questionnaire developed for the German Part of the EPIC project. European Prospective Investigation into Cancer and Nutrition. Int J Epidemiol 26, Suppl. 1, S59-S70.

28. Bohlscheid TS, Hoting I, Boeing H et al. (1997) Reproducibility and relative validity of energy and macronutrient intake of a food frequency questionnaire developed for the German Part of the EPIC project. European Prospective Investigation into Cancer and Nutrition. Int J Epidemiol 26, Suppl. 1, S71-S81.

29. Boeing H, Wahrendorf J \& Becker N (1993) EPIC-Germany - a source for studies into diet and risk of chronic diseases. Ann Nutr Metab 43, 195-204.

30. Schulze MB, Kroke A, Saracci R et al. (2002) The effect of differences in measurement procedure on the comparability of blood pressure estimates in multi-centre studies. Blood Press Monit 7, 95-104.

31. Klem ML, Klesges RC, Bene CR et al. (1990) A psychometric study of restraint: the impact of race, gender, weight and marital status. Addict Behav 15, 147-152.

32. Hainer V, Kunesova M, Bellisle F et al. (2006) The Eating Inventory, body adiposity and prevalence of diseases in a quota sample of Czech adults. Int J Obes (Lond) 30, 830-836.

33. Bellisle F, Clément K, Le Barzic M et al. (2004) The Eating Inventory and body adiposity from leanness to massive obesity: a study of 2509 adults. Obes Res 12, 2023-2030.

34. Hays NP \& Roberts SB (2008) Aspects of eating behaviors 'disinhibition' and 'restraint' are related to weight gain and BMI in women. Obesity (Silver Spring) 16, 52-58.

35. de Lauzon-Guillain B, Basdevant A, Romon $\mathrm{M}$ et al.; FLVS Study Group (2006) Is restrained eating a risk factor for weight gain in a general population? Am J Clin Nutr 83, 132-138.
36. Delahanty LM, Meigs JB, Hayden D et al. for the Diabetes Prevention Program (DPP) Research Group (2002) Psychological and behavioral correlates of baseline BMI in the diabetes prevention program (DPP). Diabetes Care 25, 1992-1998.

37. Ledoux T, Watson K, Baranowski J et al. (2011) Overeating styles and adiposity among multiethnic youth. Appetite 56, 71-77.

38. Keim NL \& Horn WF (2004) Restrained eating behavior and the metabolic response to dietary energy restriction in women. Obes Res 12, 141-149.

39. Moreira P, de Almeida MD \& Sampaio D (2005) Cognitive restraint is associated with higher intake of vegetables in a sample of university students. Eat Behav 6, 229-237.

40. Goulet J, Provencher V, Piché ME et al. (2008) Relationship between eating behaviours and food and drink consumption in healthy postmenopausal women in a real-life context. Br J Nutr 100, 910-917.

41. Van Strien T \& Van de Laar FA (2008) Intake of energy is best predicted by overeating tendency and consumption of fat is best predicted by dietary restraint: a 4-year follow-up of patients with newly diagnosed type 2 diabetes. Appetite 50, 544-547.

42. Keränen AM, Strengell K, Savolainen MJ et al. (2011) Effect of weight loss intervention on the association between eating behaviour measured by TFEQ-18 and dietary intake in adults. Appetite 56, 156-162.

43. Riesco E, Rossel N, Rusques C et al. (2009) Impact of weight reduction on eating behaviors and quality of life: influence of the obesity degree. Obes Facts 2, 87-95.

44. McGuire MT, Jeffery RW, French SA et al. (2001) The relationship between restraint and weight and weightrelated behaviors among individuals in a community weight gain prevention trial. Int J Obes Relat Metab Disord 25, 574-580.

45. Savage JS, Hoffman L \& Birch LL (2009) Dieting, restraint, and disinhibition predict women's weight change over 6 years. Am J Clin Nutr 90, 33-40.

46. Teixeira PJ, Silva MN, Coutinho SR et al. (2010) Mediators of weight loss and weight loss maintenance in middle-aged women. Obesity (Silver Spring) 18, 725-735. 